\title{
As crisis looms, how can SMEs be saved?
}

\section{Charlotte Wu}

\section{(2) OpenEdition \\ Journals}

Electronic version

URL: http://journals.openedition.org/chinaperspectives/5751

DOI: 10.4000/chinaperspectives. 5751

ISSN: 1996-4617

Publisher

Centre d'étude français sur la Chine contemporaine

\section{Printed version}

Date of publication: 30 December 2011

Number of pages: 64-66

ISSN: 2070-3449

Electronic reference

Charlotte Wu, "As crisis looms, how can SMEs be saved? », China Perspectives [Online], 2011/4 | 2011, Online since 30 December 2011, connection on 15 September 2020. URL : http://

journals.openedition.org/chinaperspectives/5751 


\section{As crisis looms, how can SMEs be saved?}

\section{Analysis by Charlotte Wu based on:}

-Yang Zhongxu, (1) Mo Li, (2) "Truth about SMEs' difficulties," Caijing, no. 23, 26 September 2011.

-Wang Li, (3) Yu Hairong, (4) "SMEs' long winter, multiple pressures could lead to aggravating the situation or towards large scale overhaul," Xin Shiji, no. 463, 15 August 2011.

- Qiu Xiaomin, (5) "Gu Shengzu: It is imperative to alleviate SMEs' existential troubles," Xinhua Wang, 1 September 2011.

-Wan Donghua, (6) "Several measures to relieve SMEs of their difficulties," Zhongguo Guoqing Guoli - China National Conditions and Strength, no. 224, 7 September 2011.

- Peng Chunlai, (7) "Gu Shengzu, six remedies for SMEs' financing difficulties," Zhengjuan Ribao, 20 September 2011.

S ince the start of the year, the difficulties of small and medium enterprises (SMEs) have made national news. The situation grew serious in April with the media speaking of an unprecedented "wave of bankruptcies" ( daobi chao 倒闭潮); but Chinese authorities flatly rejected such talk. Apart from the uncertain international economic context, three main factors lie behind SMEs' difficulties: a sharp rise in salary costs, rocketing raw material prices, and restrictive domestic monetary policy.

The phenomenon is especially noticeable in the Yangtze and Pearl River deltas, where private small-scale export industries in particular have been seriously affected. In Wenzhou City (Zhejiang Province), renowned for its entrepreneurs, 40 percent of SMEs went bankrupt, and others suspended production or shut their factories. Some SME bosses fled or committed suicide as they were unable to repay loans, often procured in the informal economy. ${ }^{\left({ }^{8}\right)}$ The contagion even spread to northern China, confirming the national character of the crisis.

This wave of bankruptcies affecting SMEs in China is of a much different nature from those closely linked to the 2008 financial crisis, which hit several national economies (and hurt SMES) around the world. In China, the difficulties are mainly linked to the firms' intrinsic weaknesses and to the complex domestic context. The persisting global economic crisis is merely a secondary cause of the difficulties they face. Some entrepreneurs think the current economic environment is much worse for Chinese SMEs than in 2008. Many different industries were seriously affected, leading some entrepreneurs towards speculation and property deals, where short-term profits are greater.

SMEs have been unable to retain staff due to sharply rising wage levels. National People's Congress Standing Committee member Gu Shengzu said during a discussion on SMEs at the Asia Pacific Economic Cooperation summit in Chengdu in August 2011 that the average wage increased by 20 to 30 percent this year. This has led some SMEs to suspend orders, fearing their inability to carry on operating, according to Caijing journalists Yang Zhongxu and Mo Li. China's labour market is gradually changing, and the abundant labour model is now a thing of the past. The interprovincial labour supply imbalance is becoming sharper, raising demand for a "new generation" of skilled migrant workers.

The second cause of difficulties is the shortage and rise in prices of imported raw materials, especially oil, on which the Chinese economy is heavily dependent.

Apart from the three factors of production, other elements adding to the SME crisis are appreciation of the yuan, various taxes, and the rising cost of land. All these elements have led to a considerable rise in SMEs' production costs.

The current tight monetary policy leading to a sharp rise in the cost of capital makes it difficult for SMEs to raise funds. The worst affected are the

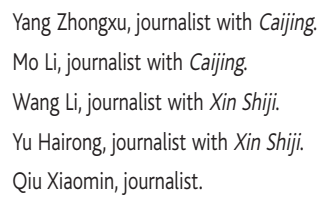

6. Wan Donghua, chief editor of Zhongguo Guoging Guoli magazine and vice-director of the Department of Rural Socio-Economic Survey, National Bureau of Statistics of China.

Peng Chunlai, journalist with Zhengjuan Ribao.

8. Informal financing arrangements among private parties outside the banking system are highly developed in China; they are actually usurious activities, with no regularisation or compensation.

9. Qiushi (Seek Truth) is the ideological journal of the Central Committee of the Communist Party of China. 
under-qualified or those lacking collateral. These SMEs are compelled to turn to informal loan markets such as pawning, with interest rates of 50 percent or even higher in some cities. According to Wang Li and Yu Hairong of Xin Shiji, underground financial networks, such as loans among private parties, are growing apace, with interest rates often far higher than the central bank's indicative rate.

With the world economy still emerging from recession and talk of a second crisis, SMEs' difficulties are growing. Economic uncertainties in Europe and the United States have led to a sharp fall in external demand for Chinese exports. As for the domestic market, following the 4 trillion yuan stimulus package unveiled in November 2008, Chinese authorities have had to tighten monetary policy since January 2010. Beijing has thus set stricter criteria for bank credit nationwide in order to fight inflation, which reached 6.2 percent on an annualised basis in August 2011, by raising bond yields 13 times in 21 months, and rates five times. Commercial banks' tight liquidity has aggravated the financial situation of SMEs.

Besides these exogenous cases, SMEs have also faced problems with management and competitiveness. China's industrial restructuring and optimisation have been too slow to help SMEs' development. Further, the imperfect market system and lack of regulation governing property rights and intellectual property create an uncertain and inefficient economic environment. Another peculiarity of the Chinese market is the focus of bank credit on major cities, especially the concentration on financing major companies. The difference between the interest rate charged to private firms and that for state-owned companies is enormous, meaning that bank credit facilities are not equitably allocated. According to Gu Shengzu, fewer than 10 percent of SMEs can obtain funding from the formal financial system, most having to deal with private loans ( minjian jiedai 民间借 贷) outside the regulated banking system. Structural problems of credit allocation have led to a rise in the interest rate imposed on private loans; this might eventually cause a financial crisis if the private loan bubble were to burst. This might well spread and have repercussions on the real economy and the formal financial system. Some experts indicate that the situation could prove disastrous in certain regions, especially in Zhejiang Province and even more so in Wenzhou City, where informal financing is very highly developed. Any break in the chain of private loans could have a domino effect, infecting the national economy.

In this climate, many entrepreneurs prefer to shut their firms and seek more viable investment opportunities. In effect, a tendency towards private capital flight from the real economy towards speculative investments yielding short-term profits has been observed. This creates a potential threat to real-world industry. Monetary policy has been ineffective in remedying the problem of liquidity shortage. Monetary authorities face difficulties in striking a balance between expansionist and restrictive policies, facing, on the one hand, SMEs that lack funding, and on the other, entities implicated in usurious and speculative activities. Premier Wen Jiabao, writing in the publication Qiushi, ${ }^{(9)}$ urged attention to long-term and cumulative consequences of monetary policies in order to ensure the crisis would not have too heavy an impact on the real economy. ${ }^{(10)}$

Silk Road Holding Group chairman Ling Lanfang ${ }^{(11)}$ was quoted by Caijing journalists as saying that all economic actors complain of difficulties with finance but that in reality the most affected were industrials. However, companies that obtained funds through connections and used them for speculating on the financial market have not lacked for funding at all. In August and September, Caijing journalists went to observe the economic situation of SMEs in Zhejiang and Guangdong provinces, which are heavily dependent on the industrial sector. They noted that few entrepreneurs remained in the real economy, many having taken to speculation while factories shut or went bankrupt.

Yang Zhongxu and Mo Li note that despite a rising chorus of voices asking for a more accommodative monetary policy, a small number of entrepreneurs warn that due to the close links between state-owned firms, banks, SMEs, private financial institutions, and property promoters, too rapid a relaxation of monetary policy would mainly benefit speculators. Most economists and officials share this view.

Caijing journalists report that this summer, the head of an industry body in Wenzhou, Zhou Dewen, ${ }^{(12)}$ established a classification of SMEs based on their evolution and activities. According to Zhou, 10 percent of SMEs seek to boost productivity, 20 percent are trying to transform their activities, and the majority are involved in speculation. He says that despite many policies unveiled by the government and the China Banking Regulatory Commission, major banks give priority to profitability and are not worried about the survival of SMEs. Major banks take the stand that it is difficult to overcome the risks linked to SME financing and thus prefer to limit exposure to them.

During the summer summit of Chinese entrepreneurs on 16 September 2011, Gu Shengzu said 60 to 70 percent of SMEs were struggling to survive, 10 percent were pursuing structural optimisation, and 20 percent were transforming their activities. Among the difficulties SMEs faced, financing problems were exacerbated in 2011 and remain most urgent. Meanwhile, the authorities in charge of industry appear not to have noticed the wave of SME bankruptcies, something Gu Shengzu said was attributable to "zombies" that had failed to declare their bankruptcy to the administration. Gu proposed six solutions to resolve the SMEs' financing difficulties, as reported by journalist Peng Chunlai:

- develop microcredit companies and small rural banks to service SMEs;

- innovate in the finance domain to facilitate access through, for instance, internet platforms for financing SMEs;

- adopt fiscal advantages or subsidies to stimulate bank credit;

- create systems of guarantors to facilitate lending to SMEs;

- relax financial control, continue liberalising interest rates and financial system reform;

- strengthen direct financing and widen the space for private capital investment.

According to Wan Donghua, in order to help SMEs emerge from this crisis, the problems have to be seen through two dimensions: those factors exogenous and endogenous to SMEs.

As for exogenous factors, a start has to be made with monetary and fiscal policies to alleviate the penury of SME financing as soon as possible. As inflationary pressure remains substantial, monetary policy will remain tight in the short term. In order to support SMEs and regularise private capital flows, microcredit companies and rural banks must be ceded a bigger role. Financial sector innovation has to be sped up, the financial market

\footnotetext{
10. Wen Jiabao, "On macroeconomic policy and economic work," Qiushi, no. 17, 1 September 2011.

11. Ling Lanfang, chairman, Silk Road Holding Group Co. Ltd.

12. Zhou Dewen, head of Wenzhou's SME Development and Promotion Association and vice-president of
} China Association of Small and Medium Enterprises. 
deregulated, and a professional organisation built to direct private capital towards the real economy. Finally, fiscal incentives for SMEs would be the way to go about resolving the problems of financial overload in China. Financial support policies such as tax reductions and temporary alleviation of fiscal burdens as well as subsidies would need to be adopted. On the other hand, the structure and functioning of the labour market has to be strengthened, working conditions have to be improved, and the industrial structure imbalance between eastern and western China has to be set right. It is also important to speed up modernisation of the agricultural sector in order to free up labour and improve worker mobility towards SMEs.

As regards endogenous factors, SMEs have to learn to adapt to a relatively unfavourable environment. They must make use of the economic and financial pressures they face (bian yali wei dongli 变压力为动力) in order to speed up transformation and modernisation of the industrial structure, speed up technological innovation, and boost labour productivity. SMEs could also create mutual aid systems or cooperate to benefit from remedial measures when needed. Meanwhile, there's no free lunch in the market system, and it is inevitable that some firms will disappear, benefiting others that might grow bigger and stronger.

In order to eventually move towards a market system with fair competition among companies and to extricate SMEs from the current crisis, the following points need attention: continue improving the market economy system, abolish outdated property rights, and facilitate companies' market access by lowering legal barriers. In order to resolve SMEs' financing problems, financial system reform has to be pursued to remedy the current situation dominated by major banks. To do this, a multi-level financing system better suited to their needs has to be gradually established through the creation of special funds backed by fiscal policies, as well as more community banks, small and medium sized commercial banks, and microcredit guaranteeing companies in non-bank financial institutions.

I Translated by N. Jayaram 